\title{
Role of internal oxidation on the failure of air plasma sprayed thermal barrier coatings with a double-layered bond coat
}

Dol:

10.1016/j.surfcoat.2017.04.026

\section{Document Version}

Accepted author manuscript

Link to publication record in Manchester Research Explorer

Citation for published version (APA):

Zou, Z., Jia, L., Yang, L., Shan, X., Luo, L., Guo, F., Zhao, X., \& Xiao, P. (2017). Role of internal oxidation on the failure of air plasma sprayed thermal barrier coatings with a double-layered bond coat. Surface and Coatings Technology, 319, 370-377. https://doi.org/10.1016/j.surfcoat.2017.04.026

Published in:

Surface and Coatings Technology

\section{Citing this paper}

Please note that where the full-text provided on Manchester Research Explorer is the Author Accepted Manuscript or Proof version this may differ from the final Published version. If citing, it is advised that you check and use the publisher's definitive version.

\section{General rights}

Copyright and moral rights for the publications made accessible in the Research Explorer are retained by the authors and/or other copyright owners and it is a condition of accessing publications that users recognise and abide by the legal requirements associated with these rights.

\section{Takedown policy}

If you believe that this document breaches copyright please refer to the University of Manchester's Takedown Procedures [http://man.ac.uk/04Y6Bo] or contact uml.scholarlycommunications@manchester.ac.uk providing relevant details, so we can investigate your claim.

\section{OPEN ACCESS}




\section{Accepted Manuscript}

Role of internal oxidation on the failure of air plasma sprayed thermal barrier coatings with a double-layered bond coat

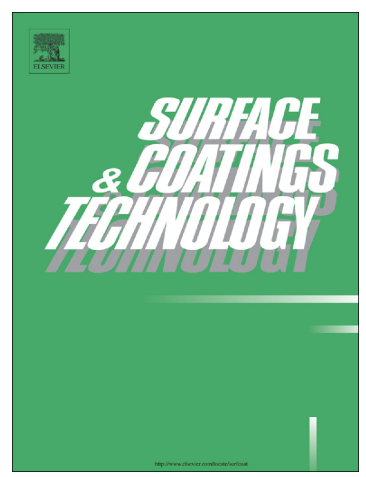

Zhonghua Zou, Libing Jia, Lixia Yang, Xiao Shan, Lirong Luo, Fangwei Guo, Xiaofeng Zhao, Ping Xiao

PII: S0257-8972(17)30372-9

DOI: doi: 10.1016/j.surfcoat.2017.04.026

Reference: SCT 22269

To appear in: Surface \& Coatings Technology

Received date: 28 February 2017

Revised date: $\quad 30$ March 2017

Accepted date: $\quad 10$ April 2017

Please cite this article as: Zhonghua Zou, Libing Jia, Lixia Yang, Xiao Shan, Lirong Luo, Fangwei Guo, Xiaofeng Zhao, Ping Xiao, Role of internal oxidation on the failure of air plasma sprayed thermal barrier coatings with a double-layered bond coat. The address for the corresponding author was captured as affiliation for all authors. Please check if appropriate. Sct(2017), doi: 10.1016/j.surfcoat.2017.04.026

This is a PDF file of an unedited manuscript that has been accepted for publication. As a service to our customers we are providing this early version of the manuscript. The manuscript will undergo copyediting, typesetting, and review of the resulting proof before it is published in its final form. Please note that during the production process errors may be discovered which could affect the content, and all legal disclaimers that apply to the journal pertain. 


\section{Role of Internal Oxidation on the Failure of Air Plasma Sprayed Thermal Barrier}

\section{Coatings with a Double-layered Bond Coat}

Zhonghua Zou ${ }^{\mathrm{a}}$, Libing Jia ${ }^{\mathrm{b}}$, Lixia Yang ${ }^{\mathrm{a}}$, Xiao Shan ${ }^{\mathrm{a}}$, Lirong Luo ${ }^{\mathrm{a}}$, Fangwei Guo ${ }^{\mathrm{a}}$, Xiaofeng Zhao ${ }^{\text {a, }}$, , Ping Xiao ${ }^{\mathrm{c}}$

${ }^{a}$ Shanghai Key Laboratory of Advanced High-temperature Materials and Precision Forming, Shanghai Jiao Tong University, Shanghai 200240, China

${ }^{\mathrm{b}}$ Gas Turbine Development Center, Corporate Technology, Siemens Ltd., China

${ }^{c}$ School of Materials, University of Manchester, Grosvenor Street, Manchester M1 7HS, UK

\section{Abstract}

Failure of air plasma sprayed (APS) thermal barrier coatings (TBCs) with a double-layered bond coat was investigated. The bond coat consists of a dense layer near the substrate side and a porous layer on the surface. Both were made of NiCoCrAlY alloy and deposited using high velocity oxygen-fuel technique. After thermal cycling, a large amount of internal oxides formed (up to $45 \%$ in volume fraction), introducing a significant volume expansion both in in-plane and perpendicular direction in the bond coat. However, the presence of the ceramic top coat can suppress the bond coat in-plane swelling thus lowering the internal oxidation rate. Compared with the fully dense bond coat, the interface roughness of the porous bond coat increases significantly when internal oxidation occurs. There is a strong correlation between the internal oxidation and the interface roughness. In addition, both the beneficial and detrimental effects of internal oxidation on TBC failure were discussed. It is proposed that a fully dense bond coat with a proper surface roughness should have a longer thermal cycling

\footnotetext{
* Corresponding author Tel./fax: +8621 54742561.

E-mail address: xiaofengzhao@sjtu.edu.cn (X. Zhao).
} 
lifetime.

Keywords: Thermal barrier coating, Bond coat, Air plasma spray, Internal oxidation, Failure 


\section{Introduction}

Air plasma sprayed (APS) thermal barrier coatings (TBCs) are widely employed in the hot sections of industrial gas turbines to protect the underlying metallic components from high temperature, and to increase the efficiency of the turbines by enabling higher turbine inlet temperature [1-5]. It is well accepted that the surface roughness and aluminum supply in the bond coats are the most critical factors for the TBC's durability. To maintain a sufficient aluminum supply for the formation of protective alumina (also termed as thermally grown oxide, TGO), a fully dense MCrAlY bond coat was usually deposited using high velocity oxy-fuel (HVOF) technique. However, the surface of a dense bond coat prepared by HVOF is relatively smooth (e.g., varying from 2 to $8 \mu \mathrm{m}$ [6]), which could not ensure a good interlocking with the yttria stabilized zirconia (YSZ) top coat. Although the rough surface of the bond coat can be achieved by HVOF, the porosity of the coating will increase [6]. To improve the surface roughness of the bond coat, a second rough MCrAlY layer, deposited using either APS or HVOF, was applied on the dense MCrAlY bond coat. For example, Nowak et al.[7] reported that the double-layered bond coat, i.e., an inner HVOF layer and an outer APS layer, could substantially extend the lifetime of the APS TBCs, due to the more "micro-rough" surface. Nevertheless, the in-flight oxidation of MCrAlY particles during APS process could decrease the aluminum content as well as inhibit the Al outward diffusion, which may shorten the lifetime of the TBC system [8-10]. To avoid this detrimental effect, the HVOF technique is employed to fabricate the rough outer layer through manipulating the powder size and spaying parameters [6], which is relatively dense and free of in-flight oxidation compared with the APS technique. In addition, there is no need to change the spraying gun during bond coat deposition. Consequently, the HVOF becomes the preference 
technique to fabricate a double-layered bond coat for the gas turbine industry and prove to prolong the lifetime of the APS TBCs.

However, it has been demonstrated that the coating porosity is proportional to the surface roughness of the HVOF bond coats [6]. To achieve a large surface roughness, the rough outer layer is relatively porous. Therefore, the internal oxidation ${ }^{1}$ of the rough bond coat layer is inevitable during long-term exposure at high temperature. Actually, the internal oxidation is a common phenomenon even for a single layered bond coat $[10,14-16]$. For example, it was reported that, for an APS bond coat, the amount of the internal oxides can be up to $50 \%$ (in volume) after 120 cycles at $1121^{\circ} \mathrm{C}$ [15]. If the internal oxidation occurs, it will cause several detrimental effects. (i) Rapid Al depletion in the bond coat could promote the formation of spinel oxides and degrade the interfacial adhesion. (ii) Internal oxides could prevent the Al outward diffusion to the interface. (iii) Local volume expansion if the internal oxidation is non-uniform, especially near the YSZ top coat, could change the interface morphology and induce interface cracking.

All of above could lead to the premature failure of the APS TBCs. However, the internal oxidation might have beneficial effects. For example, it could lower the overall coefficient of thermal expansion (CTE) of the bond coat, and thus reduce the compressive stress in the YSZ top coat (due to the CTE gradient). This should be beneficial to the TBCs lifetime because the driving force for the coating spallation is lower. However, to date, few efforts have been made to investigate on the effect of internal oxidation on the failure of the APS TBCs.

Therefore, the objective of this work is to investigate the role of internal oxidation in the failure of the APS TBCs with a double-layered HVOF bond coat. The evolution of

\footnotetext{
${ }^{1}$ The terminology "internal oxidation" means local oxidation at open porosity of the bond coat, which is different from the definition by Wagner et al. [11-13].
} 
microstructure, internal oxidation rate, e.g., internal oxides content and oxidation depth through thickness, and residual stresses in the top coat were measured. In addition, the effect of the internal oxidation on the interface roughening was also investigated. The beneficial and detrimental effects of internal oxidation on the APS TBC's failure were discussed. It is expected that these findings will help to understand the failure mechanism of the APS TBCs with a double-layered bond coat.

\section{Experimental procedure}

\subsection{Sample preparation}

In this work, the TBCs consisted of a YSZ top coat and a double-layered NiCoCrAlY bond coat on Hastelloy-X substrate. The intention of using the double-layered bond coat was to increase the surface roughness, as aforementioned. The inner bond coat was fully dense and the outer bond coat had a rough surface. Both layers were deposited by HVOF but with different spraying parameters, using the same NiCoCrAlY alloy powder (Amdry 365-2, Oerlikon Metco). Prior to the deposition of the top coats, all bond coats were annealed in vacuum at $1120{ }^{\circ} \mathrm{C}$ for 24 hours. Then the top coats were deposited by APS using $\mathrm{ZrO}_{2}-8$ wt. $\%$ $\mathrm{Y}_{2} \mathrm{O}_{3}$ powder (8YSZ, Metco 204B NS, Oerlikon Metco). The thicknesses of inner and outer bond coats and the top coat are $\sim 230 \mu \mathrm{m}, \sim 175 \mu \mathrm{m}$ and $\sim 400 \mu \mathrm{m}$, respectively. A fully dense single layered NiCoCrAlY bond coat was also prepared for comparison, using the same powder with the double-layered bond coat.

\subsection{Thermal exposure}

The button shaped samples, with $25.4 \mathrm{~mm}$ in diameter and $3 \mathrm{~mm}$ in thickness, were used for thermal cycling lifetime test, which consisted of 10 -minute heat up to $1150{ }^{\circ} \mathrm{C}, 23.5$-hour dwell at $1150{ }^{\circ} \mathrm{C}$ and followed by a 20 -minute air cooling. The TBCs failure was defined as 
the spallation area was greater than $10 \%$. At least 10 samples were used for thermal cycling life test. After required exposure, some specimens were removed from the furnace for residual stresses and microstructure examination. To evaluate the surface roughness and volume changes of the bond coat, isothermal exposure instead of thermal cycling was also conducted at $1150{ }^{\circ} \mathrm{C}$. At least 5 samples were used for each condition.

\subsection{Quantitative analysis of internal oxides}

The polished cross-sections were observed using a scanning electron microscope (SEM, FEI F50) coupled with an energy dispersive spectrometer (EDS, Oxford). The volume fraction of internal oxides was quantified by image analysis using ImageJ software. All the images were taken from the cross section in backscattered electron mode with $1500 \mu \mathrm{m} \times 1300 \mu \mathrm{m}$ field of view and numerical resolution $\sim 0.68 \mu \mathrm{m} / \mathrm{pixel}$. At least six randomly selected areas, with sampling area of greater than $1.2 \mathrm{~mm}^{2}$, were analyzed. The interface TGO layer was not taken into account in the measurement of the internal oxides fraction.

\subsection{Roughness characterization}

The changes of interface roughness should be investigated as one possible cause to interface cracking, due to some internal oxides generated close to the interface. The top coat/TGO interface roughness was also quantified based on cross-sectional SEM micrographs, using the procedure described elsewhere [17]. For the bond coats, the surface roughness was investigated using a profilometer (Zegage, Zygo, USA). Each measurement covered a field with $2 \mathrm{~mm} \times 8 \mathrm{~mm}$, and at least five measurements were carried out.

\subsection{Raman spectroscopy}

The YSZ stresses were evaluated using Raman spectroscopy. Raman spectra were collected using a confocal Raman microprobe system (LabRAM HR Evolution, Horiba, Jobin 
Yvon, France) coupled with a $532 \mathrm{~nm}$ excitation. The laser beam was focused on the surface of the YSZ top coat through a $50 \times(0.75 \mathrm{NA})$ objective lens. Small pieces of as-sprayed coating were scraped off and each annealed in air with different time, as the stress-free samples. At least 20 positions were randomly selected. All the spectra were fitted by a mixed Lorentzian-Gaussian function to obtain the peak position. The Raman band at $465 \mathrm{~cm}^{-1}$ was selected for stress measurement because of its large stress-induced peak shift and can be well separated from the other peaks [18].

\section{Results}

\subsection{Microstructure evolution during thermal exposure}

Fig. 1 shows the cross-sectional microstructure of the as-sprayed APS TBC with a double-layered bond coat. The rough bond coat surface $(\mathrm{Ra}, 18.5 \mu \mathrm{m})$ was achieved by the double-layered structure, as the bond coat/top coat interface shown in Fig. 1a. Some poor melted NiCoCrAlY particles were observed in the outer layer bond coat for the sake of a rough surface (Fig. 1b), which caused pores and inter-splat gaps (Fig. 1c). The inner bond coat is a relatively dense layer (Fig. 1d). The porosity of inner and outer layer is approximate $1.2 \%$ and $3.5 \%$, respectively. Both layers show the same phase composition, which consists of $\beta$-NiAl (gray contrast, 41.5 vol. \%) and $\gamma$-Ni phase (bright contrast).

The internal oxides generated at the open porosity between the poor melted splats during thermal exposure, as shown in Fig. 2a. The outer bond coat layer (internal oxidation layer) became a composite layer consisting of internal oxides and metallic phases. The formation of the internal oxides is non-uniform, especially close to the interface. Pores and cracks are observed in internal oxides, as shown in Fig. 2b. The internal oxides are mainly alumina, which were identified by the EDS analysis. It suggests that the inner bond coat can supply 
sufficient $\mathrm{Al}$ to fulfill the formation of protective $\mathrm{Al}_{2} \mathrm{O}_{3}$ before the coating failure, despite a rapid Al-depletion by internal oxidation. Mixed oxides are also observed locally between the top coat and TGO (predominantly $\mathrm{Al}_{2} \mathrm{O}_{3}$ ), which is a common phenomenon in most thermal sprayed NiCoCrAlY bond coats after oxidation. However, the mixed oxides was formed early on the surface of the double-layered bond coat than the dense bond coat with the same thermal exposure time, due to a high depletion rate of $\mathrm{Al}$ in the former. Generally, the delamination of the TBCs located at the top coat/TGO interface as shown in Fig. 3. Most interface TGO is bonded well onto the bond coat side.

\subsection{Internal oxidation rate}

To quantify the internal oxidation, it is necessary to measure the changes of internal oxides fraction during the thermal cycling. The dependence of internal oxide fraction with the thermal cycles is plotted in Fig. 4a. There is a rapid increase in the first five cycles, followed by a linear increase with a low rate. The internal oxides fraction is about $38 \%-44 \%$ for the failed TBCs. As the increase of internal oxides, the thicknesses of the outer bond coats also increase. Fig. $4 \mathrm{~b}$ plots the thickness changes of the inner and outer bond coat layers. Here the two bond coat layers are distinguished by whether contains the internal oxides, because the internal oxides mainly formed in the outer bond coat layers. The thickness of the outer bond coat layer has a rapid increase in the first five cycles, then follows a linear increase, while the thicknesses of the dense inner bond coat layer decrease with the increase of thermal cycles. One possibility is that oxygen can also infiltrate into the inner layer along the inter-splat boundaries during internal oxidation.

Although the YSZ is transparent to oxygen [19], different internal oxidation rates appear in the samples with/without the YSZ top coats, as shown in Fig. 5. The bond coats were only 
annealed to 100 hours to avoid the effect of TGO delamination (or spallation) on internal oxidation rate. The amount of internal oxides in the bond coat is nearly two times of the sample with the YSZ top coat under the same annealing time. Fig. 6 presents the corresponding cross-sectional microstructure of the samples with/without the YSZ top coat. For the bond coats, the TGO spallation and open cracks (black arrows) in the outer bond coat layer is observed (Fig. 6a). With the YSZ top coats, the TGO layer is still intact and no open cracks within the outer bond coat layer (Fig. 6b). It indicates that these open cracks in the outer bond coats were suppressed with the constraint of the YSZ top coat. Then the lower infiltration rate of oxygen into the bond coat will reduce the extent of internal oxidation.

\subsection{Volume expansion in bond coats}

It is well known that the transformation of most pure metal or alloy to oxides will cause volumetric expansion [20]. The internal oxidation will induce the volumetric expansion of the bond coat perpendicular and parallel to the YSZ top coats. The dependence of total thickness of the bond coat (TGO layer not included) with thermal cycles was plotted in Fig. 7. Following a significant increase (first 5 cycles), the total thickness of the bond coat shows a linear increase with the increase of thermal cycles. It is up to $16 \%$ after 61 thermal cycles, as shown by the inset in Fig.7.

To observe the in-plane swelling, four cross-sections of each sample were ground and polished prior to thermal exposure. In-plane swelling was observed in the outer bond coat layer (Fig. 8a). However, there is different extent of the bond coats swelling between the samples with/without YSZ top coats. The in-plane swelling in the bond coats is nearly three times than the samples with the YSZ top coats. One of the primary cause should be the more internal oxides formed in the former, as shown in Fig. 5. 
Although the internal oxidation should be one cause to volumetric expansion of the bond coats, there may be other factors, e.g., inter-diffusion between the bond coats and substrate. The volume changes of a fully dense bond coat were also compared (Fig. 8c). There is no apparent swelling in the dense bond coat during thermal exposure. It suggests that the volumetric expansion of the bond coat is less affected by the inter-diffusion between the bond coat and substrate than the internal oxidation.

\subsection{Surface/interface roughness}

It is accepted that the bond coat/top coat interface morphology plays a key role in the APS TBCs lifetime [7, 21]. However, it is unknown whether the interface morphology changes with the formation of significant internal oxides. As shown in Fig. 9a, the top coat/TGO interface roughness increased continuously until the coating failure. The interface roughness, $\mathrm{Ra}$, of the failed samples increases by $1 \mu \mathrm{m}$ than that of the intact samples.

To confirm the effect of internal oxidation on interface roughening, the surface roughness evolution for the double-layered was compared with the dense bond coat, as shown in Fig. 9b (solid line). There is no surface roughening of the dense bond coats, while significant increase occurs in the double-layered bond coats. Since different deposition parameters, initial roughness value is different between the double-layered and the dense bond coats. To eliminate the difference in initial roughness, the tests were conducted again using these two types of bond coats with polished surfaces (dash line in Fig. 9b). Although there is slight increase in surface roughness of the dense bond coat, the double-layered bond coat shows a higher increase. The roughness evolution in bond coats with either rough (sprayed) or smooth (polished) surfaces suggests that the internal oxidation may play a key role in the surface roughening of the double-layered bond coat. 
Since there is no internal oxide in the dense bond coat, the surface rumpling was mainly induced by the TGO stresses (either the growth stress or the thermal misfit stress between the TGO and the substrate) $[22,23]$. For the sprayed dense bond coat, the surface is rough $(\mathrm{Ra} \approx$ $16 \mu \mathrm{m})$. Both the growth stress and thermal misfit stress can be significantly released, leading to a much lower TGO stress compared with the polished bond coat. Therefore, the surface rumpling for the sprayed bond coat is lower than the polished one. In addition, the oxide formed on the sprayed bond coat (i.e., rough surface) is not uniform, which also shadow the change of the surface roughness. Contrastly, the polished bond coat has a smooth surface, and the TGO formed is uniform. Therefore, the roughness change shows a clear trend than the sprayed bond coat.

\subsection{Residual stresses in TBCs}

The residual stress in the top coat is usually considered as one of the driving forces for TBC failure $[24,25]$, and the presence of the significant internal oxides may affect the stresses in the top coat. Hence, the stress in the YSZ layer was measured by Raman technique using the approach employed by Limarga et al. [26]. Since the top coat is much thinner than the substrate, the coating stress can be approximated to a biaxial stress, $\sigma_{\text {in-plane }}$, which can be calculated from the Raman peak shift, $\Delta v$, as follows [26]:

$$
\sigma_{\text {in-plane }}=\frac{1-v_{T B C}}{2 \Pi} \frac{E_{T B C}}{E_{\text {dense }}} \Delta v
$$

where, $v_{T B C}$ is the Poisson's ratio of the top coat, which is $0.25 ; E_{T B C}$ and $E_{\text {dense }}$ is the in-plane Young's modulus $(E)$ of the plasma sprayed and the fully dense YSZ, which is $\sim 50$ GPa and $210 \mathrm{GPa}$ [26], respectively; $\Pi$ is the piezospectroscopic (PS) coefficient for the dense 7YSZ under uniaxial stress, which is $2.01 \mathrm{~cm}^{-1} / \mathrm{GPa}$ for $465 \mathrm{~cm}^{-1}$ [18]. It should be noted that the measured stresses represent the stress state near the top coat surface, since the 
Raman spectroscopy sampling depth was found to be $\sim 40 \mu \mathrm{m}$ in APS YSZ [27].

Fig. 10 shows the measured residual stresses in the top coats as a function of thermal cycles. At as-sprayed condition, the residual stress in the top coats is tensile ( $\sim 80 \mathrm{MPa})$, which is the superposition of the quenching stress and the thermal stress induced by CTE mismatch during cooling after spraying [28]. After thermal exposure, the tensile stresses gradually transform to compressive stresses (up to $-50 \mathrm{MPa}$ ) until 11 cycles. The change of stress state in the top coat is possibly affected by the following two factors. (i) The creep of the coatings and substrate could reduce the tensile stress in the top coat at high temperature. (ii) The sintering leads to an increase of the Young's modulus of the top coat. Then the compressive stress component induced by the thermal misfit between the top coat and the substrate should be the predominantly stress component. After 18 cycles, the compressive stress gradually decreased to zero. This is because the cracking generated at the top coat/TGO interface (the inset shown in Fig. 10), which releases the stress in the top coat. In addition, the outer bond coat layer with internal oxidation can be considered as an intermediate layer with a low CTE, which may share part of the CTE stress between the substrate and the top coat.

\section{Discussion}

Based on the above results, the internal oxidation resulted in the volumetric expansion of bond coats. The presence of the YSZ top coat constrained the swelling of the bond coat and lowered the internal oxidation rate. The internal oxidation was the primary cause for the increase of interface roughness. The internal oxidation has benefit and detriment to the TBC's durability, as discussed below.

\subsection{Effect of internal oxidation on the TBCs stresses}

The formation of internal oxides should result in a low CTE and a high Young's modulus 
of the outer bond coat. According to the rule of mixture, the CTE and the Young's modulus of the outer bond coat layer can be expressed by:

$$
\begin{aligned}
\alpha & =\frac{f \alpha_{I} E_{I}+(1-f) \alpha_{M} E_{M}}{f E_{I}+(1-f) E_{M}} \\
E & =f E_{I}+(1-f) E_{M}
\end{aligned}
$$

where, $f$ is the volume fraction of the internal oxides, and the subscript $I$ and $M$ represents the internal oxides and metal phase in the outer bond coat, respectively. The CTE of metal phase (predominantly $\gamma$-Ni) and internal oxides (predominantly $\alpha-\mathrm{Al}_{2} \mathrm{O}_{3}$ ) are approximately $13 \times 10^{-6} / \mathrm{K}$ and $8 \times 10^{-6} / \mathrm{K}$ at room temperature [29], respectively; the Young's modulus of the metal phase and $\alpha-\mathrm{Al}_{2} \mathrm{O}_{3}$ are approximately $200 \mathrm{GPa}$ and $375 \mathrm{GPa}$ [29], respectively. The dependence of the calculated CTE and Young's modulus of the outer bond coat on the internal oxides fraction was plotted in Fig. 11. The CTE of the outer bond coat decreases with the increase of the internal oxides fraction. With more than 20 vol.\% internal oxides, it is very close to that of the APS YSZ, $9.7 \times 10^{-6} / \mathrm{K} \sim 11 \times 10^{-6} / \mathrm{K}[26,29,30]$. The Young's modulus of the outer bond coat increases with the increase of internal oxides, which is significantly higher than that of the substrate (Fig. 11b). These changes in bond coats should affect the CTE misfit stress gradient between the top coat and the substrate.

The CTE misfit stresses in the multilayer are calculated based on elastic solution [31]. The schematic of the calculated model is shown in Fig. 12. Three layers with individual thickness $t_{i}$ are bonded sequentially to a substrate with a thickness, $t_{s}$. The coordinate system defined such that the interface between the substrate and $1^{\text {st }}$ layer is located at $\mathrm{z}=0$, the substrate's free surface is located at $\mathrm{z}=-t_{s}$. The interface between layers $i$ and $i+1$ is located at $h_{i}$. With these definitions, the relation between $h_{i}$ and $t_{i}$ is described by, 


$$
h_{i}=\sum_{j=1}^{i} t_{j} \quad(i=1 \text { to } 3)
$$

The in-plane stresses in the substrate and coatings, $\sigma_{\mathrm{s}}$ and $\sigma_{i}$, are related to thermal strains by [31],

$$
\begin{array}{ll}
\sigma_{s}=\frac{E_{s}\left(c+k\left(z-t_{b}\right)-\alpha_{s} \Delta T\right)}{1-v_{s}} & \left(\text { for }-t_{s} \leq z \leq 0\right) \\
\sigma_{i}=\frac{E_{i}\left(c+k\left(z-t_{b}\right)-\alpha_{i} \Delta T\right)}{1-v_{i}} & (\text { for } i=1 \text { to } 3)
\end{array}
$$

In equations (5) and (6),

$$
\begin{gathered}
c=\frac{\left(E_{s} t_{s} \alpha_{s}+\sum_{i=1}^{3} E_{i} t_{i} \alpha_{i}\right)}{E_{s} t_{s}+\sum_{i=1}^{3} E_{i} t_{i}} \Delta T \\
t_{b}=\frac{-E_{s} t_{s}^{2}+\sum_{i=1}^{3} E_{i} t_{i}\left(2 h_{i-1}+t_{i}\right)}{2\left(E_{s} t_{s}+\sum_{i=1}^{3} E_{i} t_{i}\right)} \\
k=\frac{3\left[E_{s}\left(c-\alpha_{s} \Delta T\right) t_{s}^{2}-\sum_{i=1}^{3} E_{i} t_{i}\left(c-\alpha_{i} \Delta T\right)\left(2 h_{i-1}+t_{i}\right)\right]}{E_{s} t_{s}^{2}\left(2 t_{s}+3 t_{b}\right)+\sum_{i=1}^{3} E_{i} t_{i}\left[6 h_{i-1}^{2}+6 h_{i-1} t_{i}+2 t_{i}^{2}-3 t_{b}\left(2 h_{i-1}+t_{i}\right)\right]}
\end{gathered}
$$

where, $c$ is a uniform strain component in the multilayer by thermal misfit; $t_{b}$ is the location of the bending axis; $k$ is the curvature. The thickness parameters are displayed in Fig. $4 \mathrm{~b}$, and the materials properties required are summarized in Table 1 and Fig. 11. It should be noted that the properties of materials at room temperature are used. In all cases, the TBCs are assumed to be stress-free at annealing temperature. The coating system is cooled to room temperature $(298 \mathrm{~K})$ from $1423 \mathrm{~K}, \Delta T=-1125 \mathrm{~K}$.

The thermal misfit stresses were calculated for in the TBC system with 18 thermal cycles (Fig. 13), since the interface cracking was observed. The CTE misfit stresses in as-sprayed TBCs (assumed cooling from $1423 \mathrm{~K}$ to room temperature) were also calculated for comparison. The greatest difference in the stress distribution occurs in the outer bond coat. Significant compressive stresses present in the internally oxidized outer bond coat. Although the residual stresses in the top coat decrease with the internal oxidation, it is still compressive 
and just decreases by $17 \%(\sim 50 \mathrm{MPa})$. In addition, this difference in the top coat stresses could be smaller if the creep deformation of the bond coats was considered. Since the coating spallation mainly occurs at top coat/TGO interface, the stresses in the top coat will directly affect the driving force to interface cracking [32]. Therefore the presence of the internal oxides in the outer bond coat layer may play a minor role to extend the APS TBCs lifetime.

\subsection{Effect of internal oxidation on interface cracking}

The distribution of the internal oxides is non-uniform, which may cause local volumetric expansion in the bond coat close to the interface. It may be the primary cause to the interface roughening, then induces interface cracking. Fig. 14 shows the dependence of the roughness increase on the internal oxides fraction. With the YSZ top coat, the TGO/top coat interface roughness will have an apparent increase when the internal oxides fraction increases to $30 \%$ $35 \%$. The increase in TGO/top coat interface roughness can be up to $1.5 \mu \mathrm{m}$. Without the YSZ top coat, a larger increase measured from the bond coat surface was observed. In particular, a rapid increase took place at the low internal oxides fraction, e.g., $10 \mathrm{vol} \%$. The roughness increase in bond coat surface can be up to $4 \mu \mathrm{m}$. It indicates that the presence of the top coat can suppress the interface roughening at the beginning of internal oxidation. However, the interface roughening will occur when the internal oxides fraction reaches a critical point, e.g., 30 vol.\% (corresponding for the occurrence of the interface cracking). Since the internal oxidation generates continuously, the TBCs will fail eventually.

The schematics of the internal oxidation and the failure mode of the APS TBCs with a double-layered bond coat are summarized in Fig. 15. The oxygen will infiltrate into the porous bond coat along the inter-splat boundaries during the thermal exposure. Then the internal oxides will form at the open porosity in the porous bond coat, which induces the 
thickening and in-plane swelling of the bond coat. The internal oxidation will induce the TGO/top coat interface roughening, which is the mainly cause to the interface cracking. Finally, the delamination of the coating will occur at the TGO/top coat interface.

Although a rough surface of the bond coat should be beneficial to the APS TBC's durability [7], these bond coats are preferred to have a dense structure to avoid the internal oxidation. The internally oxidized bond coat plays a minor role to improve the TBC's durability. Instead, it can result in the TGO/top coat interface roughening, which directly induces the interface cracking. The disadvantages of the internal oxidation outweigh its advantages for the APS TBCs with a double-layered bond coat.

\section{Concluding remarks}

The failure of APS TBC with a double-layered NiCoCrAlY bond coat was investigated. The delamination of the top coat mainly located at the top coat/TGO interface after thermal cycling test. Significant internal oxidation was observed due to the relatively porous structure of outer bond coat. The major findings can be summarized as follows:

1) Internal oxidation plays a key role in the volumetric expansion of the bond coat, and the inter-diffusion between the bond coats and substrate has less effects. The presence of the top coat can suppress the in-plane swelling of the outer bond coat thus lowering the internal oxidation rate.

2) Internal oxidation is also the dominant cause for the TGO/top coat interface roughening, which is a direct factor to the TBC's failure. A small amount of internal oxides cannot result in TGO/top coat interface roughening with the constraint of the top coat. The top coat delamination will generate if the TGO/top coat interface roughness increases more than $1 \mu \mathrm{m}$. 
3) The presence of internal oxides plays a minor role in decreasing the CTE misfit stress in the top coat. Instead, the TGO/top coat interface roughening will directly induce the delamination. The internal oxidation may be more detrimental than beneficial for the APS TBCs with a double-layered bond coat.

\section{Acknowledgements}

The authors would thank the financial support from the "1000 Plan Program", the Program for Professor of Special Appointment (Eastern Scholar) at Shanghai Institutions of Higher Learning (No. SHDP201303), the National Natural Science Foundation of China (No. 51271120) and (No. 51402058), and the fund of Shanghai Committee of Science and Technology (No. 14ZR1422900). 


\section{References}

[1] N. Curry, N. Markocsan, X. Li, A. Tricoire, M. Dorfman, Next generation thermal barrier coatings for the gas turbine industry, J. Therm. Spray Technol. 20 (2010) 108-115.

[2] T.M. Yonushonis, Overview of thermal barrier coatings in diesel engines, J. Therm. Spray Technol. 6 (1997) 50-56.

[3] R. Vassen, M.O. Jarligo, T. Steinke, D.E. Mack, D. Stover, Overview on advanced thermal barrier coatings, Surf. Coat. Technol. 205 (2010) 938-942.

[4] U. Schulz, B. Saruhan, K. Fritscher, C. Leyens, Review on advanced EB-PVD ceramic topcoats for TBC applications, Int. J. Appl. Ceram. Technol. 1 (2004) 302-315.

[5] B. Gleeson, Thermal barrier coatings for aeroengine applications, J. Propul. Power 22 (2006) 375-383.

[6] B. Rajasekaran, G. Mauer, R. Vassen, Enhanced characteristics of HVOF-sprayed MCrAlY bond coats for TBC applications, J. Therm. Spray Technol. 20 (2011) 1209-1216.

[7] W. Nowak, D. Naumenko, G. Mor, F. Mor, D.E. Mack, R. Vassen, L. Singheiser, W.J. Quadakkers, Effect of processing parameters on MCrAlY bondcoat roughness and lifetime of APS-TBC systems, Surf. Coat. Technol. 260 (2014) 82-89.

[8] S. Deshpande, S. Sampath, H. Zhang, Mechanisms of oxidation and its role in microstructural evolution of metallic thermal spray coatings-Case study for Ni-Al, Surf. Coat. Technol. 200 (2006) 5395-5406.

[9] S. Sampath, X.Y. Jiang, J. Matejicek, L. Prchlik, A. Kulkarni, A. Vaidya, Role of thermal spray processing method on the microstructure, residual stress and properties of coatings: an integrated study for Ni-5 wt.\%Al bond coats, Mater. Sci. Eng. A 364 (2004) 216-231.

[10] H.E. Evans, M.P. Taylor, Diffusion cells and chemical failure of MCrAlY bond coats in thermal-barrier coating systems, Oxid. Met. 55 (2001) 17-34.

[11] C. Wagner, Theoretical analysis of the diffusion processes determing the oxidation rate of Alloys, J. Electrochem. Sci. 99 (1952) 369-380.

[12] M.W. Brumm, H.J. Grabke, B. Wagemann, The oxidation of NiAl-III. Internal and 
intergranular oxidation, Corros. Sci. 36 (1994) 37-53.

[13] A. Madeshia, An amendment to the classical model of internal oxidation: Model-inherent transition characteristics, Corros. Sci. 68 (2013) 111-118.

[14] R. Eriksson, S. Johansson, H. Brodin, E. Broitman, L. Östergren, X. Li, Influence of substrate material on the life of atmospheric plasma sprayed thermal barrier coatings, Surf. Coat. Technol. 232 (2013) 795-803.

[15] T. Patterson, A. Leon, B. Jayaraj, J. Liu, Y.H. Sohn, Thermal cyclic lifetime and oxidation behavior of air plasma sprayed CoNiCrAlY bond coats for thermal barrier coatings, Surf. Coat. Technol. 203 (2008) 437-441.

[16] P. Niranatlumpong, C.B. Ponton, H.E. Evans, The failure of protective oxides on plasma-sprayed NiCrAlY overlay coatings, Oxid. Met. 53 (2000) 241-258.

[17] V.K. Tolpygo, D.R. Clarke, On the rumpling mechanism in nickel-aluminide coatings: Part II: characterization of surface undulations and bond coat swelling, Acta Mater. 52 (2004) 5129-5141.

[18] A.M. Limarga, D.R. Clarke, Piezo-spectroscopic coefficients of tetragonal-prime yttria-stabilized zirconia, J. Am. Ceram. Soc. 90 (2007) 1272-1275.

[19] A.C. Fox, T.W. Clyne, Oxygen transport by gas permeation through the zirconia layer in plasma sprayed thermal barrier coatings, Surf. Coat. Technol. 184 (2004) 311-321.

[20] J. Stringer, Stress generation and relief in growing oxide films, Corros. Sci. 10 (1970) 513-543.

[21] M. Ahrens, R. Vassen, D. Stover, Stress distributions in plasma-sprayed thermal barrier coatings as a function of interface roughness and oxide scale thickness, Surf. Coat. Technol. 161 (2002) 26-35.

[22] D.S. Balint, J.W. Hutchinson, An analytical model of rumpling in thermal barrier coatings, J. Mech. Phys. Solids 53 (2005) 949-973.

[23] Y. Chen, X. Zhao, M. Bai, L. Yang, C. Li, L. Wang, J.A. Carr, P. Xiao, A mechanistic understanding on rumpling of a NiCoCrAlY bond coat for thermal barrier coating applications, Acta Mater. 128 (2017) 31-42. 
[24] S.J. Howard, Y.C. Tsui, T.W. Clyne, The effect of residual stresses on the debonding of coatings-I. A model for delamination at a bimaterial interface, Acta Metall. Mater. 42 (1994) 2823-2836.

[25] A. Bartlett, A.G. Evans, M. Rühle, Residual stress cracking of metal/ceramic bonds, Acta Metall. Mater. 39 (1991) 1579-1585.

[26] A.M. Limarga, R. Vaßen, D.R. Clarke, Stress distributions in plasma-sprayed thermal barrier coatings under thermal cycling in a temperature gradient, J. Appl. Mech. 78 (2011) 011003-1-011003-9.

[27] D. Liu, O. Lord, O. Stevens, P.E.J. Flewitt, The role of beam dispersion in Raman and photo-stimulated luminescence piezo-spectroscopy of yttria-stabilized zirconia in multi-layered coatings, Acta Mater. 61 (2013) 12-21.

[28] Y.C. Tsui, T.W. Clyne, An analytical model for predicting residual stresses in progressively deposited coatings Part 1: Planar geometry, Thin Solid Films 306 (1997) 23-33.

[29] K.W. Schlichting, N.P. Padture, E.H. Jordan, M. Gell, Failure modes in plasma-sprayed thermal barrier coatings, Mater. Sci. Eng. A 342 (2003) 120-130.

[30] M. Gupta, K. Skogsberg, P. Nylén, Influence of topcoat-bondcoat interface roughness on stresses and lifetime in thermal barrier coatings, J. Therm. Spray Technol. 23 (2014) 170-181.

[31] C.H. Hsueh, Thermal stresses in elastic multilayer systems, Thin solid films 418 (2002) $182-188$.

[32] M.R. Begley, D.R. Mumm, A.G. Evans, J.W. Hutchinson, Analysis of a wedge impression test for measuring the interface toughness between films/coatings and ductile substrates, Acta Mater. 48 (2000) 3211-3220. 


\section{Figure Captions}

Fig. 1 SEM images of as-sprayed APS TBCs with a double-layered bond coat: (a) the overall view of the TBC system and (b) the bond coat under low magnification, (c) the outer bond coat and (d) the inner bond coat under high magnification.

Fig. 2 SEM images of the TBCs with a double-layered bond coat after 5 thermal cycles $(\sim 117$ hours at $1150^{\circ} \mathrm{C}$ ), (a) low magnification, (b) high magnification close to the interface.

Fig. 3 A SEM image of the delamination of the APS TBCs after 34 thermal cycles.

Fig. 4 Changes in the bond coat during thermal cycling test, (a) the internal oxides fraction and (b) the thickness of inner and outer bond coat. Note: The error bars are the standard deviation of the measurements in this and any other figures, unless otherwise stated.

Fig. 5 Comparison of the internal oxides fraction in the samples with/without top coat during isothermal exposure at $1150{ }^{\circ} \mathrm{C}$.

Fig. 6 Comparison of the cross-sectional microstructure after 100 hours at $1150{ }^{\circ} \mathrm{C}$, (a) the bond coat and (b) the sample with a top coat.

Fig. 7 Dependence of total thicknesses of the double-layered bond coats on thermal cycles.

Fig. 8 Comparison of the in-plane swelling: (a) the double-layered bond coat with a YSZ top coat, (b) the double-layered bond coat, (c) the single layered dense bond coat. All the samples were isothermal annealed 100 hours at $1150^{\circ} \mathrm{C}$.

Fig. 9 Roughness evolution in (a) the TGO/top coat interface during the thermal cycling and (b) the bond coat surfaces during isothermal exposure.

Fig. 10 The evolution of the residual stresses in the top coats during thermal cycling; the inset shows the interface cracking in the sample with 18 cycles.

Fig. 11 The calculated values of (a) CTE and (b) Young's modulus of the outer bond coat with 
different internal oxides fraction.

Fig. 12 The schematic of the multilayer systems for the thermal misfit stresses calculation.

Fig. 13 The calculated thermal misfit stresses in the TBC systems.

Fig. 14 The dependence of the roughness increases on the internal oxides fraction.

Fig. 15 Summarized schematics of internal oxidation process and failure modes for the APS TBCs with a double-layered bond coat. 
Table 1 Summarized materials properties [26, 29]

\begin{tabular}{lll}
\hline Material & Elastic Modulus $(\mathrm{GPa})$ & CTE $\left(10^{-6} / \mathrm{K}\right)$ \\
\hline Hastelloy-X & 200 & 15 \\
NiCoCrAlY & 200 & 13 \\
APS-YSZ & 50 & 10.5 \\
\hline
\end{tabular}


Fig. 1
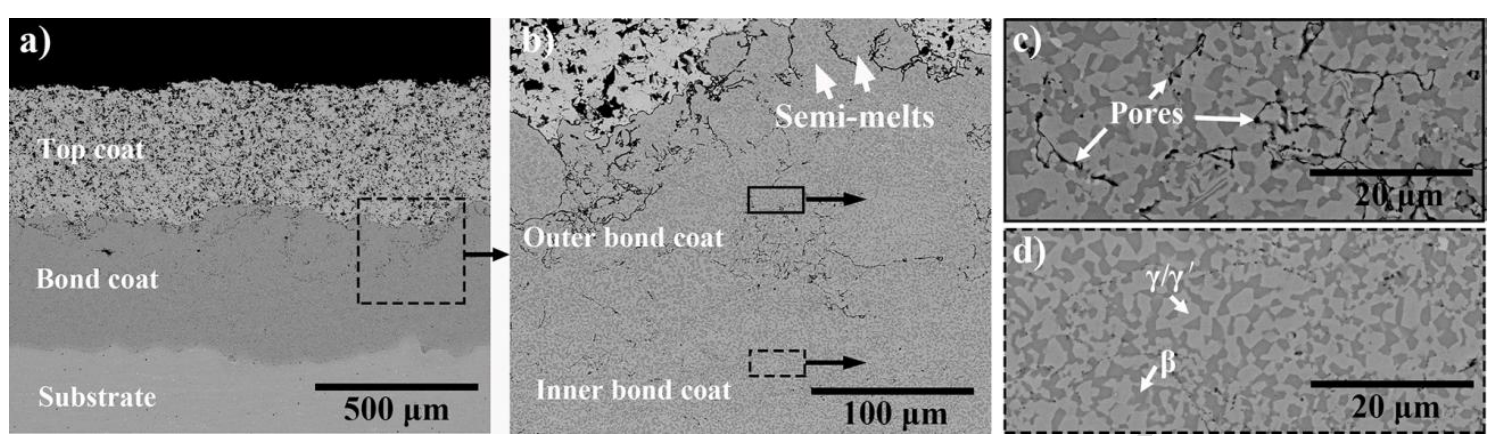
Fig. 2
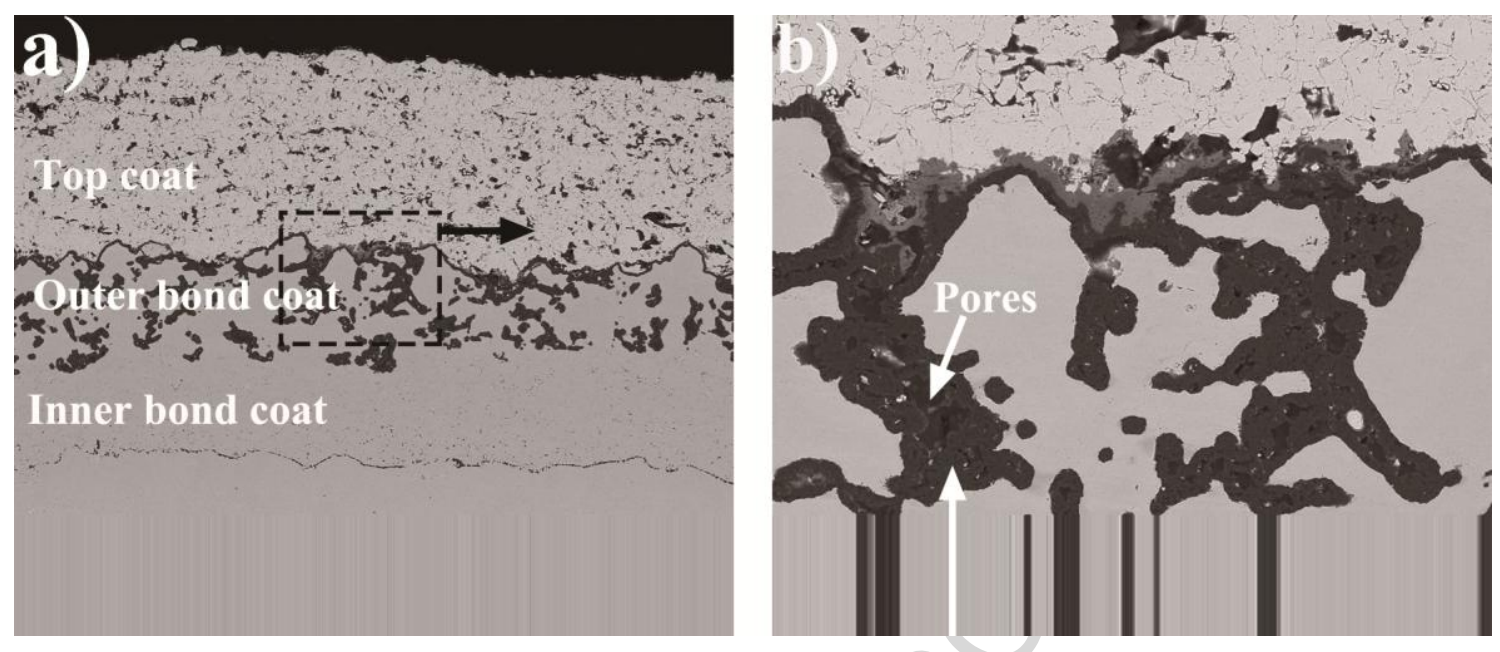
Fig. 3

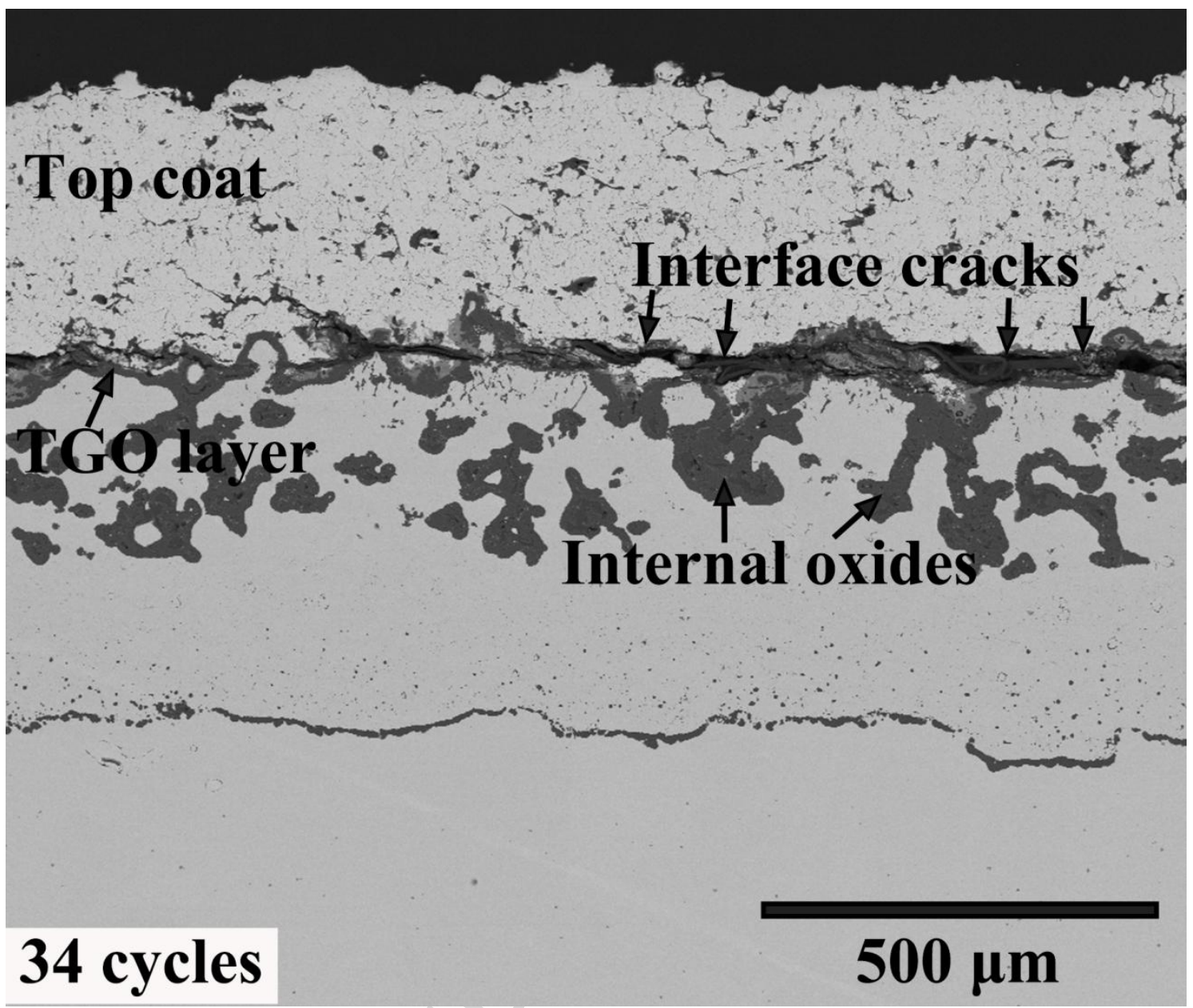


Fig. 4
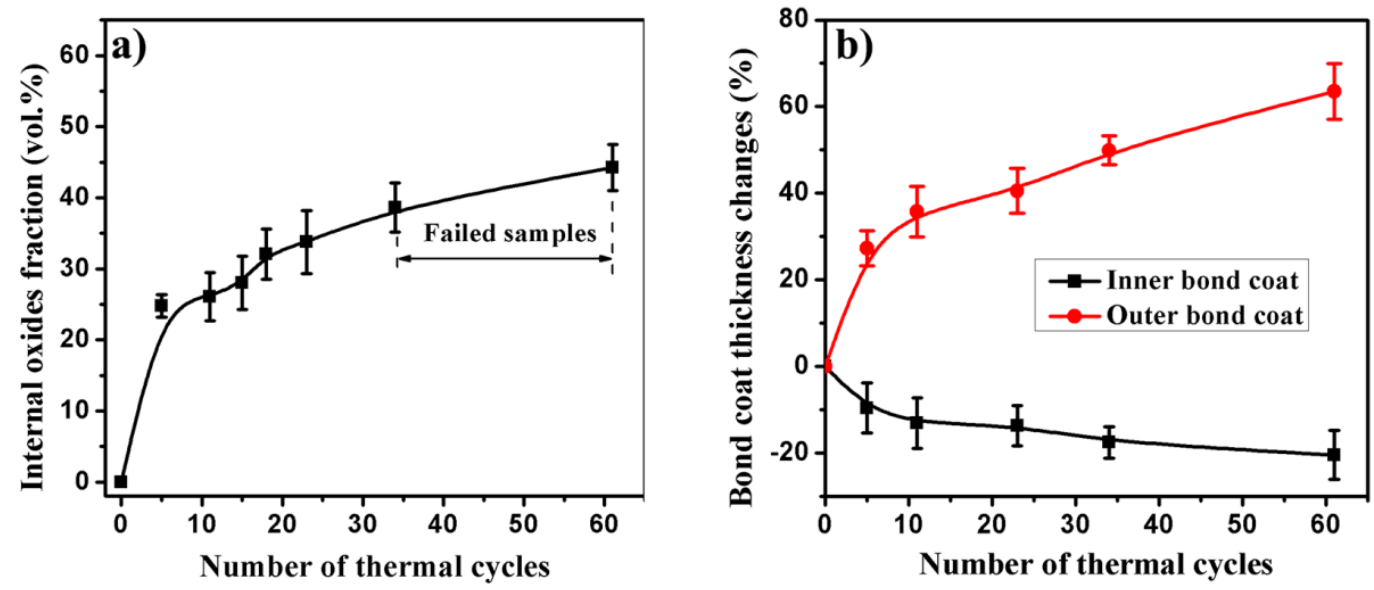
Fig. 5

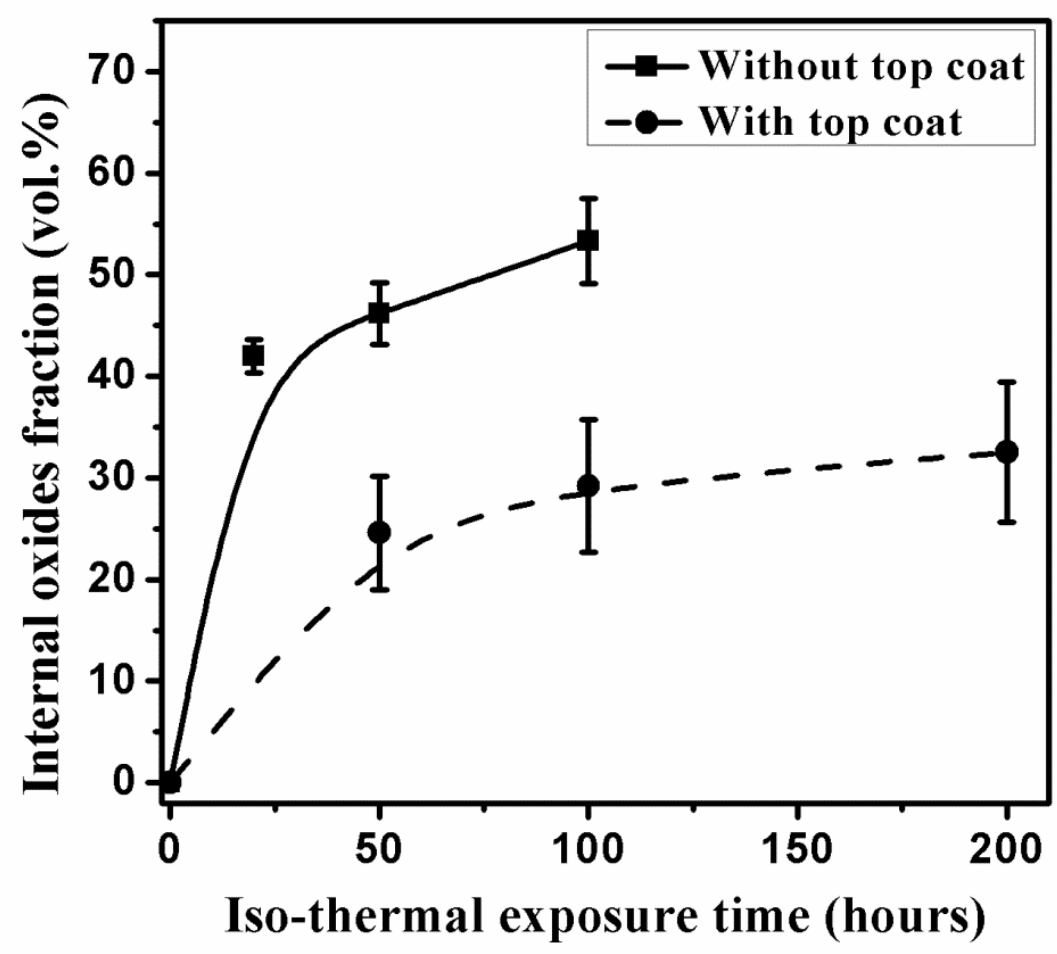


Fig. 6
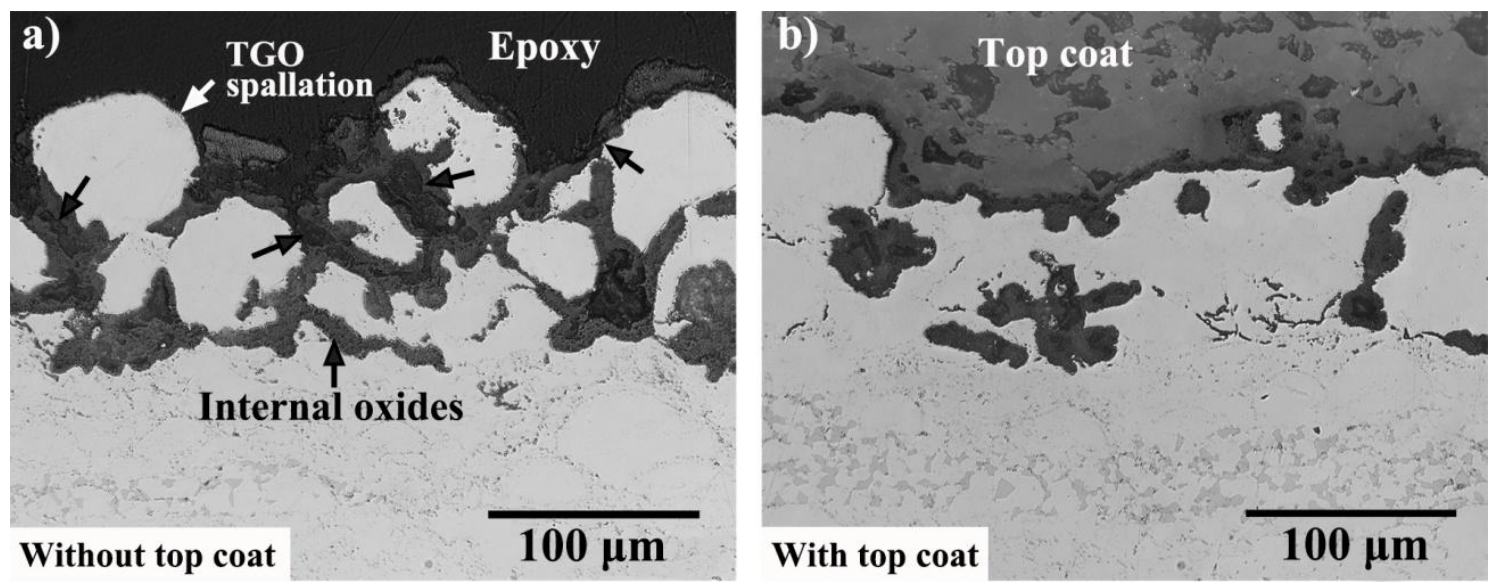
Fig. 7

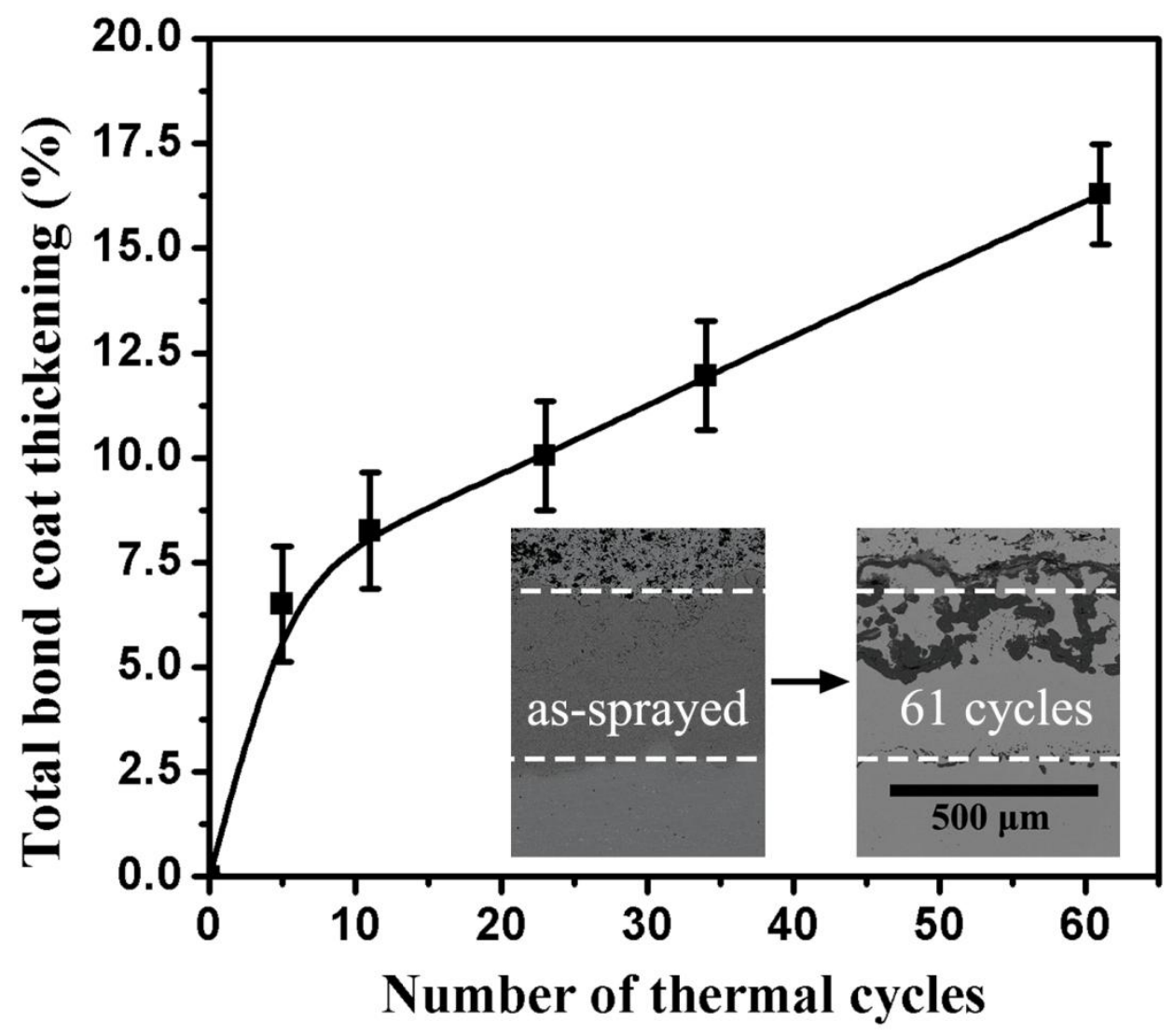


Fig. 8
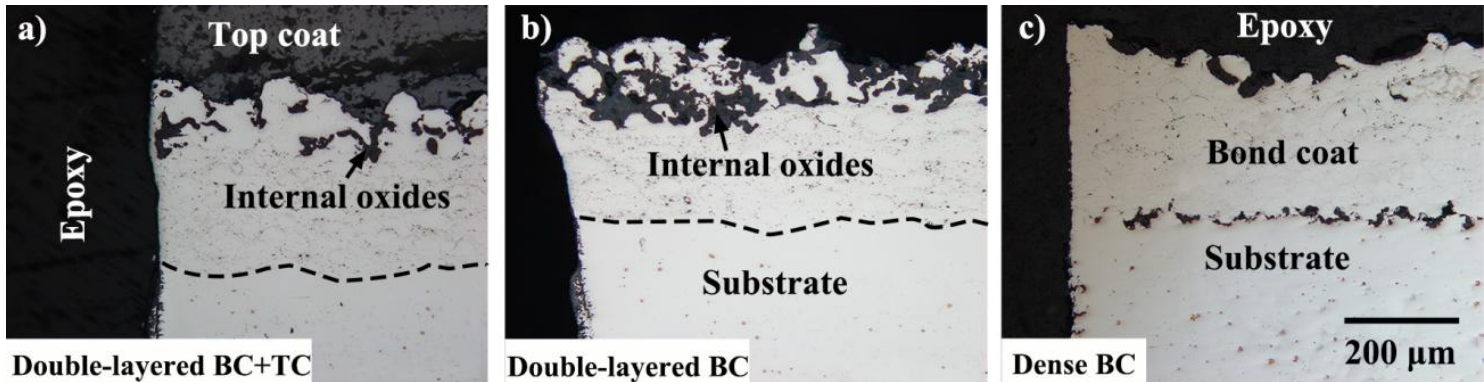

Double-layered BC+TC 
Fig. 9
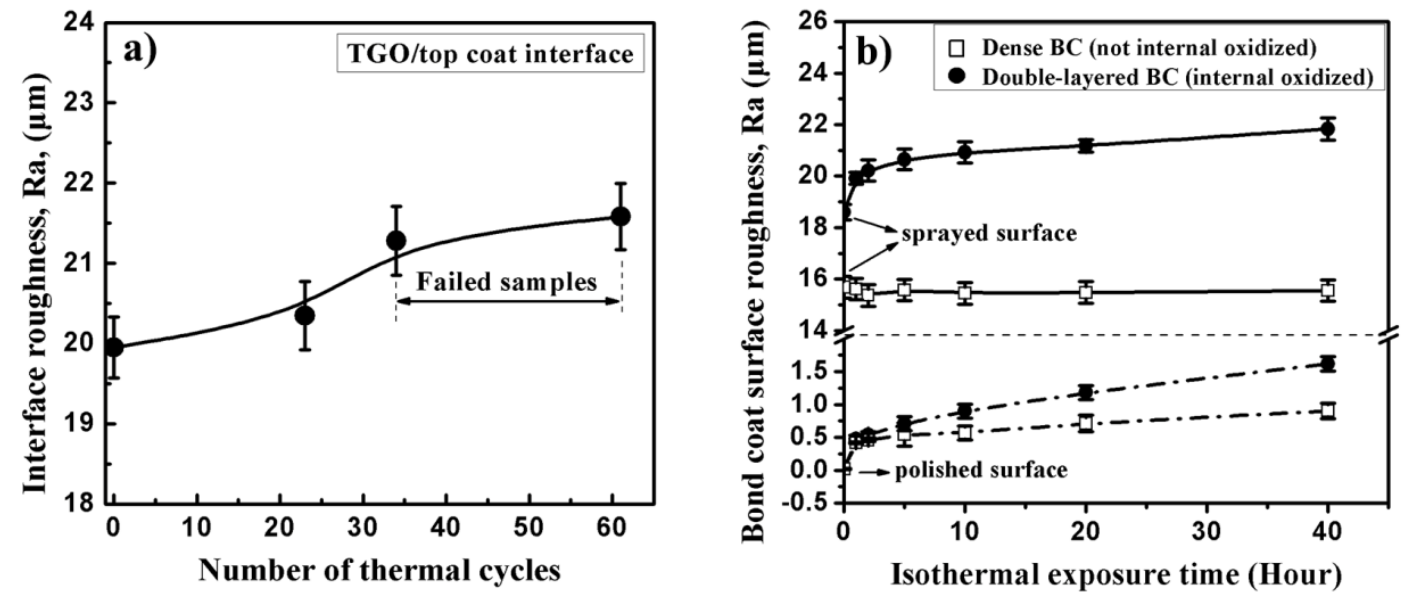
Fig. 10

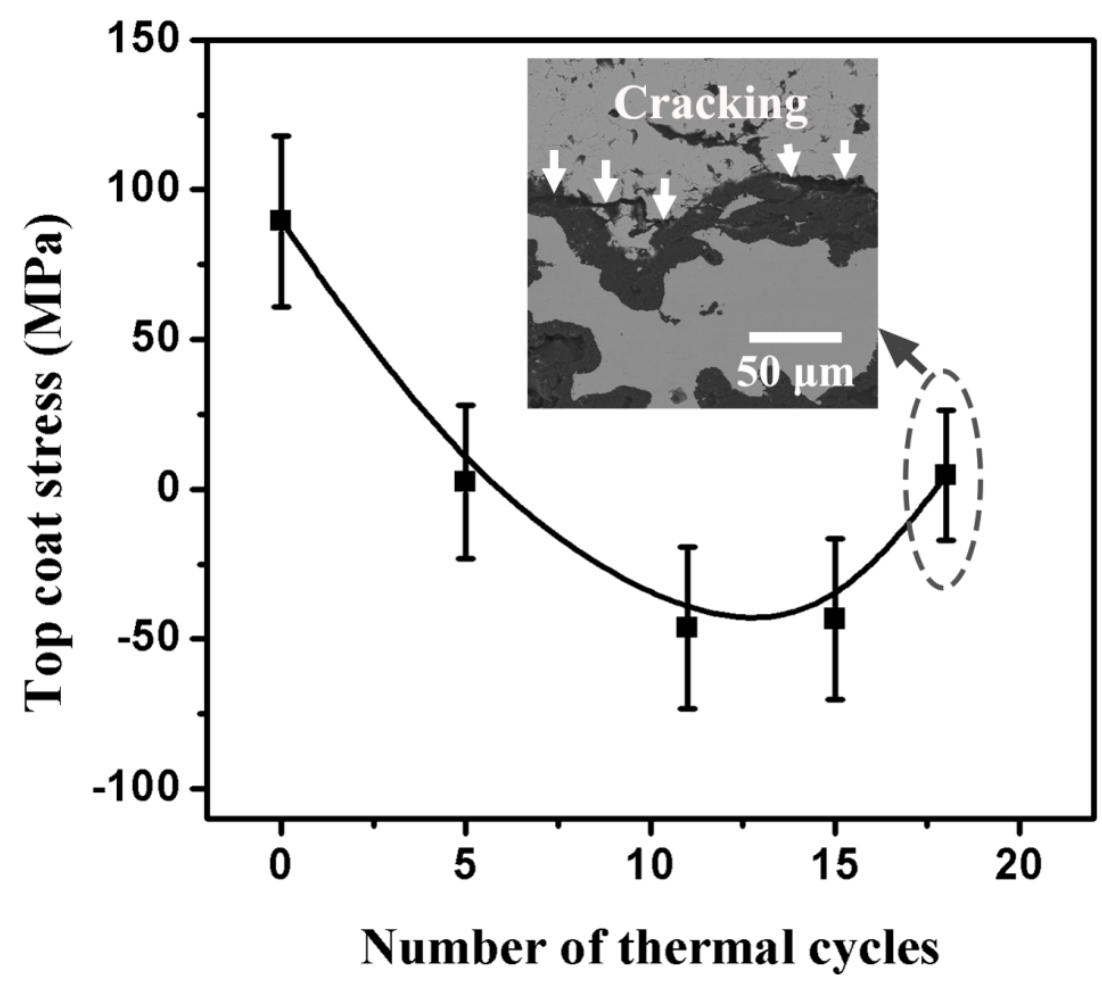


Fig. 11

a)

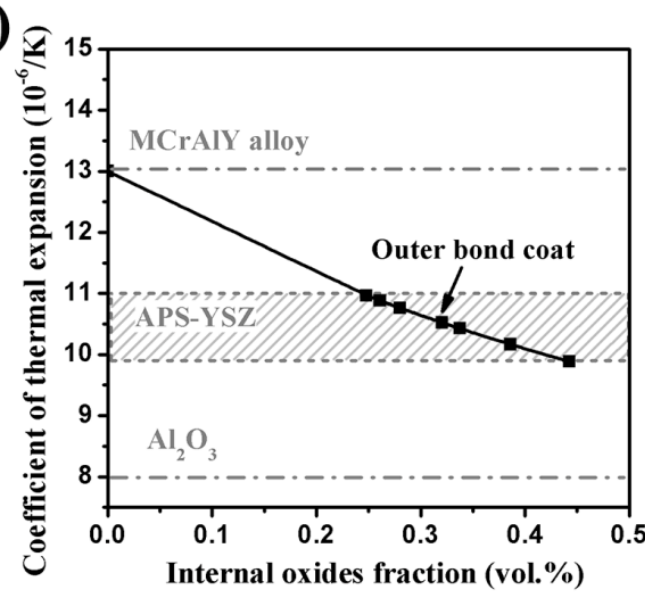

b)

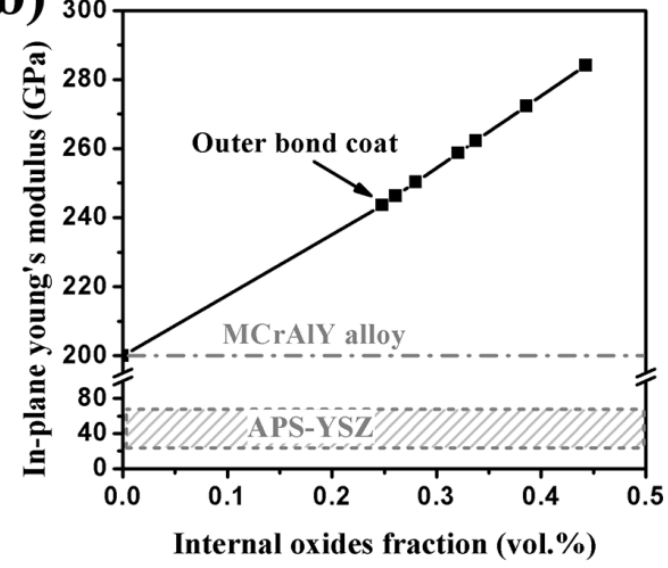


Fig. 12

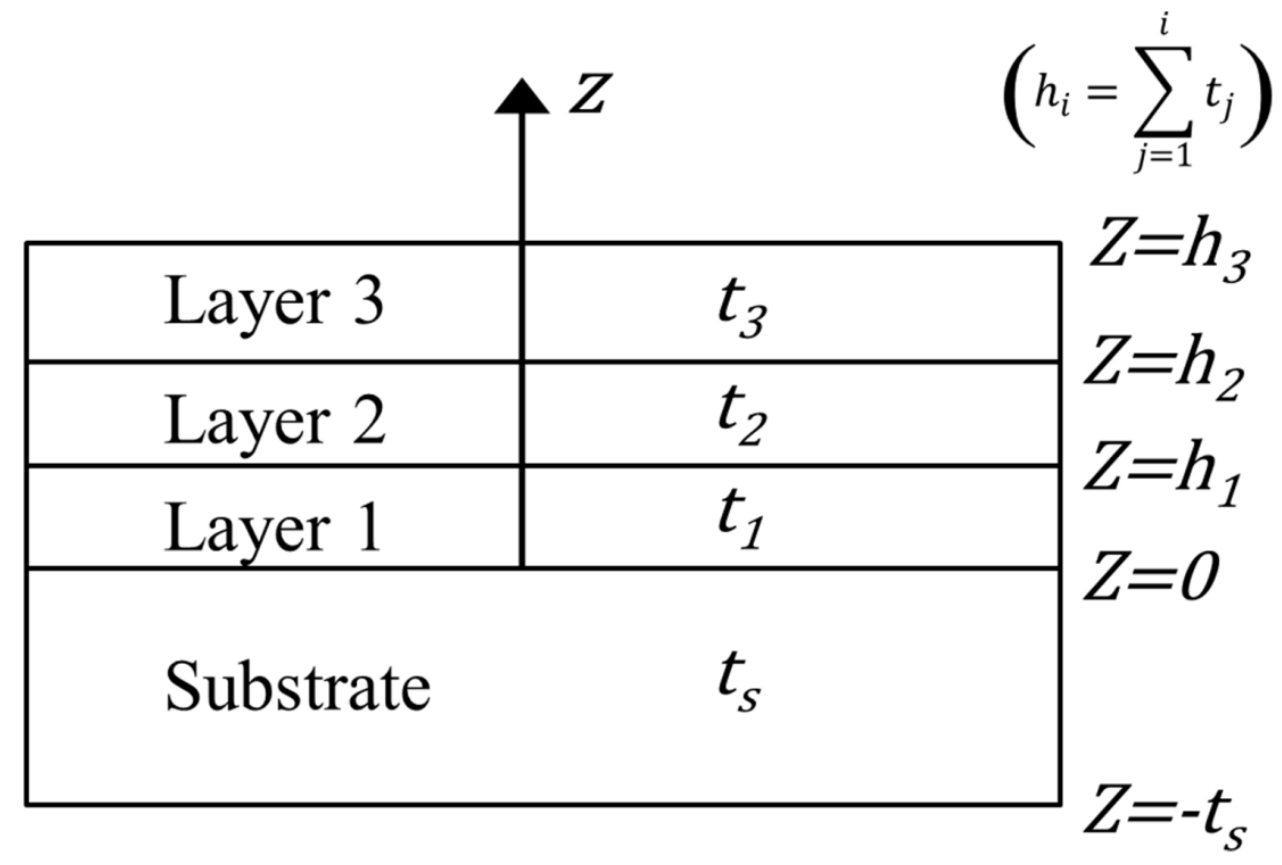


Fig. 13

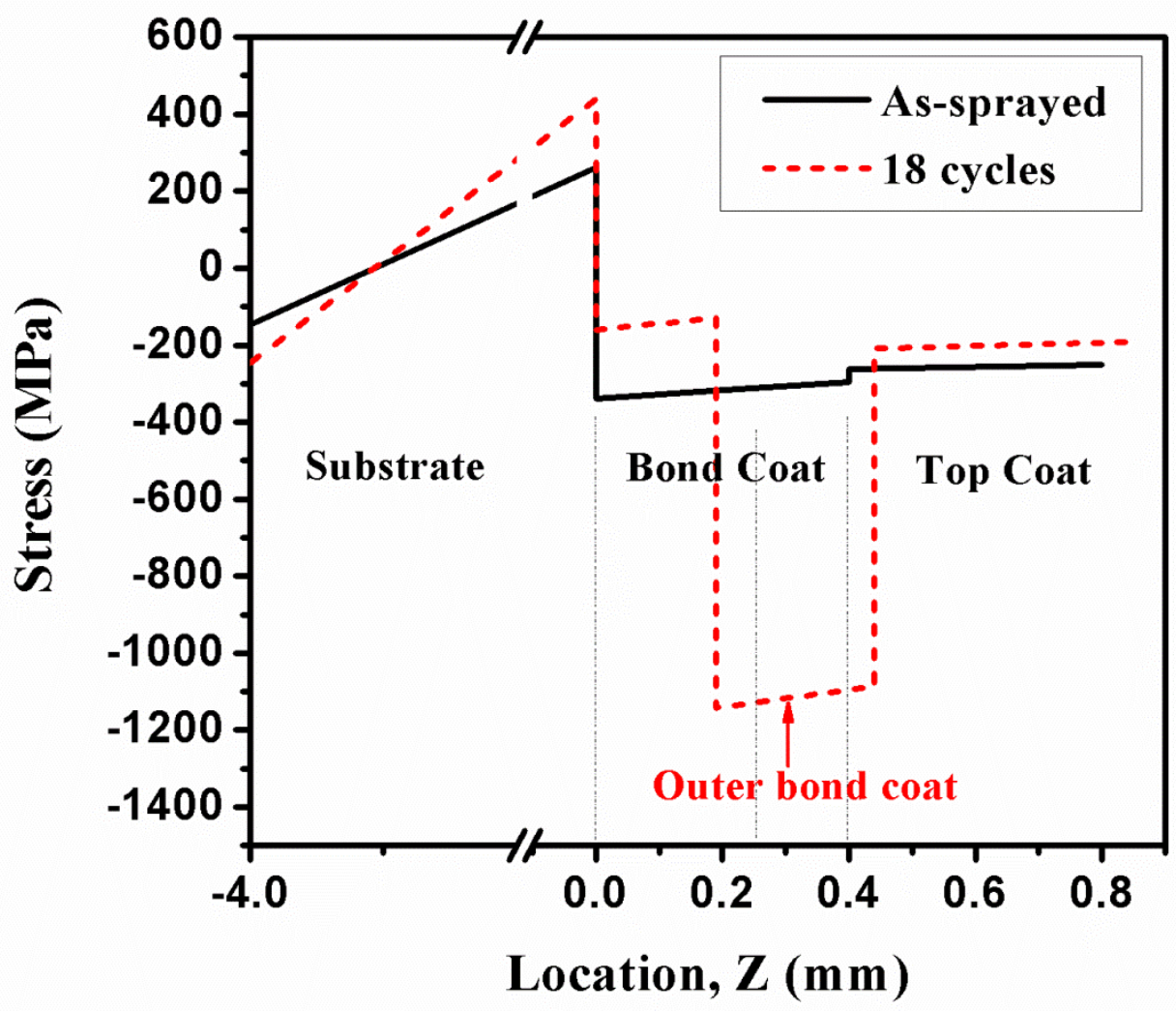


Fig. 14

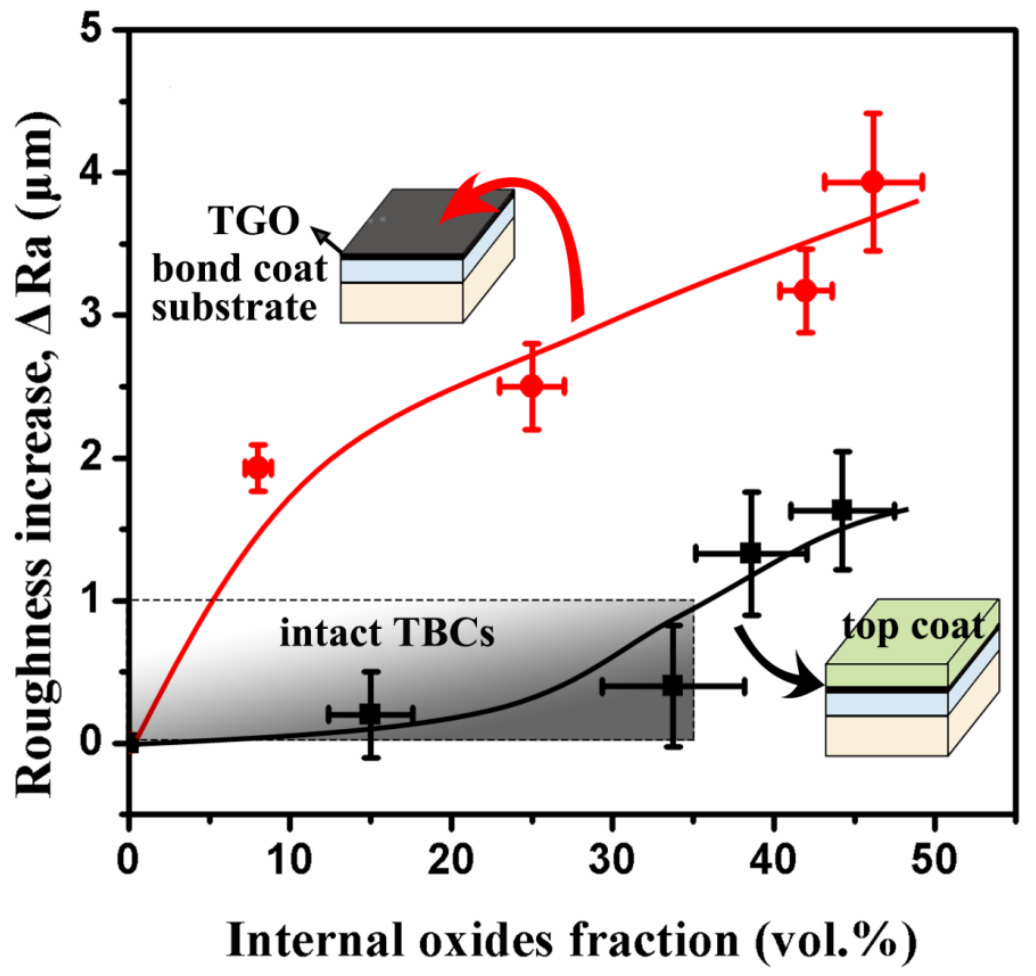


Fig. 15
a) As-sprayed
b) Thermal cycling

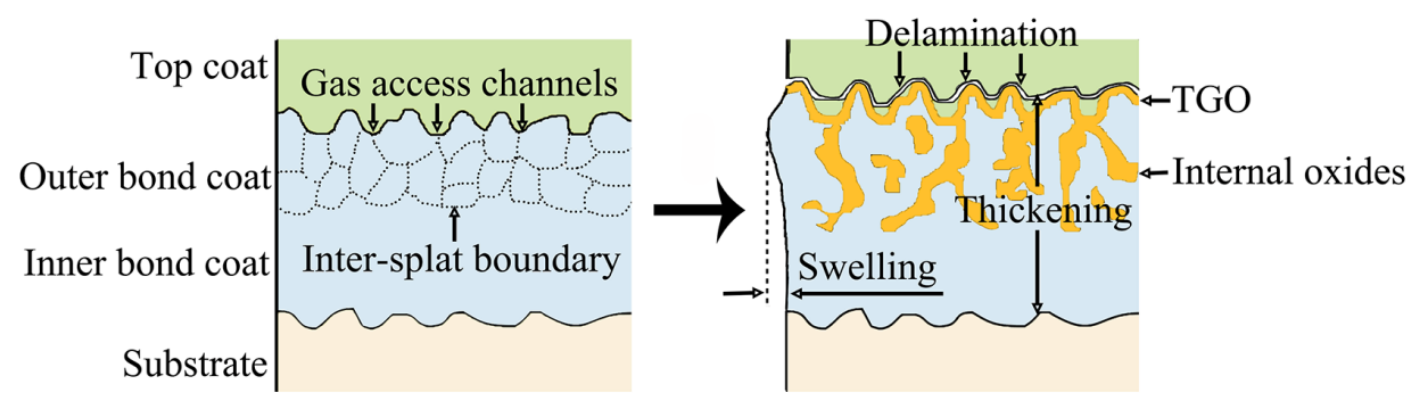




\section{Highlights:}

Failure of APS TBCs with a double-layered bond coat was investigated.

Internal oxidation is a dominant factor for the TGO/top coat interface roughening. Internal oxidation leads a significant volumetric expansion in the bond coat.

YSZ top coat can suppress bond coats swelling thus reduce the internal oxidation.

A dense bond coat with a rough surface is good for the thermal cycling life. 